\title{
EXPERIMENTAL ANALYSIS OF THE MECHANICAL BEHAVIOR OF CLAY-CEMENT BLOCKS REINFORCED WITH COCONUT FIBERS
}

\author{
CONAND HONORÉ KOUAKOU*1, MORO OLIVIER BOFFOUE ${ }^{1}$, ANGE \\ CHRISTINE DJOHORE ${ }^{1}$, KOFFI CLÉMENT KOUADIO ${ }^{1}$, EDJIKÉMÉ \\ EMERUWA $^{1}$ \\ ${ }^{I}$ Felix Houphouet-Boigny University, UFR-STRM, Laboratory Geomaterials and Habitat
Technologies, 22 BP 582 Abidjan 22, Cote d'Ivoire
}

\begin{abstract}
This article aims for analyzing under an axial stress, the behavior of earth blocks reinforced by various proportions of coconut fibers. For this fact, compressive and flexural tests were carried out after 28 days of maturation, on dry blocks elaborate with clay stabilized at $8 \%$ of cement and containing 0 to $1 \%$ of fibers $30 \mathrm{~mm}$ length. The experimental results show that the incorporation of fibers in the blocks improves their mechanical characteristics, increases their ductile deformation and delays their cracking. The best mechanical resistances are obtained at $0.8 \%$ of fibers because at this content, the distance between fibers is optimal.
\end{abstract}

Keywords: blocks, coconut fibersc ductilityc brittle fracture, distance between fibers

\section{INTRODUCTION}

The incorporation of vegetable material into the earth for the elaboration of building materials is a method traditionally used to improve the mechanical performance and durability of blocks of earth. Cowpat, for example, is mixed with earth, sand or other elements and is used as a binder or mortar because of its waterproofing and solidity. Examples of this use exist in France, China, Hungary, Africa [1]. In addition, these materials, which have a very long lifespan, form a significant part of traditional UNESCO World Heritage buildings.

Their elaboration requires a low consumption of fossil fuels and are recognized as environmentally friendly. Also, considering the concepts of sustainable development and these eco-construction corollaries, has it motivated the development of elaboration technique and the multiplication of earth-based materials including earth-vegetable fiber mixtures. The latter arouse some interest in construction because not only of the abundance and the diversity of fibers but especially of their practically zero cost. However, the use of earth- vegetable fiber composites must meet the standards related to their use in construction. Thus, certain experimental studies have focused on the addition of vegetable fibers such as sisal, straw, flax, bamboo, hemp, fiber from oil palm nuts, coconut fiber to the earth material [2-5].

The incorporating coconut fibers into adobes can increase their compressive strength [6]. It achieved a $25 \%$ improvement in maximal compressive strength accompanied by an increase in ductility. However, according to [7], the compressive strength of blocks of earth, particularly adobes, decreases with the increase in the rate of fibers of straw and incorporated date palm. However, their flexural strength is maximum when the fiber content is $2 \%$. Beyond this value, it decreases.

\footnotetext{
* Corresponding author, email: honore_kouakou2@yahoo.fr

(C) 2021 Alma Mater Publishing House
} 
Other works have focused on CEC blocks, compressed earth concretes blocks. Thus, according to [8] the increase in the coconut fiber content in bricks based on compressed laterite clay leads to a decrease in the adhesion stress, resulting in a reduction in compressive strength. However, [9] studying the incorporation of sisal fibers, cassava powder and cement in earth blocks (CEC), has shown, the existence of sisal limit values, for which there is a considerable increase in the compressive and flexural strength in the dry state of compressed earth blocks. Outside these limit values, the presence of sisal fibers has an unfavorable effect on the strength of the blocks. For [10] the compressive strength of fiber bricks is improved by the addition of $3 \%$ palm fibers. However, according to [11] with $0.05 \%$ of date palm fibers the resistance to dry compression of earth blocks containing $8 \%$ of cement and compacted with a stress of $10 \mathrm{MPa}$ is improved. Studying the incorporation of cassava peels in CEC indicates an increase in the dry compression of the mixtures, which is useful in reducing falls caused by problems with handling CEC [12]. Likewise, [5] found an increase in the compressive strength of CEC with the use of 0.2-0.8\% by weight of hibiscus cannabinus fibers (Kenaf), $30 \mathrm{~mm}$ in length, without any chemical stabilizer. The authors explain that there is always an optimum for which the fiber increases the mechanical properties.

These numerous research's studies on the effects of the incorporation of vegetable fibers in adobes and CEC cause some problems. The authors did not carry out investigations on the arrangement of the fibers in the earth matrix. This matrix bonds (adheres) less effectively with the surface of the fibers compared to the resins which establish chemical bonds with the latter. The composite's response to the various mechanical stresses would be subject to the organization of its structure. This is the reason why the mechanical behavior of the earth blocks during axial loading has been analyzed.

The aim of this work is to analyze variations in the behavior of blocks of earth reinforced by different proportions of coconut fibers. It aims to identify the effect of fibers on the behavior of earth blocks and to establish a relation between their resistance to compressive and flexural strength. For this, earth blocks reinforced with coconut fibers were tested. The results obtained are presented and discussed in this article.

\section{EXPERIMENTAL SETUP}

\subsection{Clay and cement}

The clay used was extracted from Dabou, near the Agnéby village (SW of Abidjan). The cement is a Portland cement composite (CEM II) distributed by the "Société des Matériaux d'Abidjan" (SOCIMAT) under the brand name "BELIER".

\subsubsection{Particle size distribution}

The particle size distributions of this clay were carried out by sieving and then by sedimentometry for the fraction less than $63 \mu \mathrm{m}$, while those of the cement were examined using a laser granulometer. The data collected made it possible to construct the distribution chart of the particles of these different raw materials according to their size.

\subsubsection{Chemical composition}

The proportions of the major oxides contained in the clay and the cement were estimated using an X-ray fluorescence spectrometer. The analysis was carried out on the fraction of size less than $63 \mu \mathrm{m}$.

\subsubsection{Mineralogical characterization}

The mineralogy analysis of clay and cement was carried out by X-ray diffraction on the fine fraction. The diffractometer used is of Siemens brand and the X-rays are produced by a cobalt anticathode of wavelength 1.789 $\AA$. The peaks were identified using EVA software.

\subsection{Coconut fiber}

The vegetable fibers used are coconut fibers extracted from the coconut husk. Their diameter varies between 0.1 and $1 \mathrm{~mm}$. They were cut into pieces $30 \mathrm{~mm}$ long for making the blocks. These fibers were subjected to characterization tests. These are the density determination, the measurement of water absorption capacity and the tensile strength. All these tests were carried out according to standards

\subsection{Block's elaboration}

This elaboration is done in several stages. First $8 \%$ cement and coconut fibers $30 \mathrm{~mm}$ long, in mass proportions of $0 ; 0.2 ; 0.4 ; 0.6 ; 1 \%$ is added to the clay powder and all is dry mixed for $30 \mathrm{~s}$. Then the amount of water necessary is added to obtain a paste of normal consistency with sagging at the Abrams cone corresponds to $32 \mathrm{~mm}$. This 
corresponds to the different water- material ratios contained in Table 1 . The whole is mixed until a homogeneous mixture is obtained visibly. Finally, the paste obtained is poured into $4 \times 4 \times 16 \mathrm{~cm}^{3}$ molds and then stored in a room at a temperature of $26{ }^{\circ} \mathrm{C}$ and constant humidity (70\%). Three (3) days after shaping, the specimens are removed from the mold and kept in the same room until 28 days of age.

Table 1. Formulation of the different specimens.

\begin{tabular}{|c|c|}
\hline Mass proportion of fibers (\%) & Water-material ratios \\
\hline 0 & 0.60 \\
\hline 0.2 & 0.62 \\
\hline 0.4 & 0.63 \\
\hline 0.6 & 0.64 \\
\hline 0.8 & 0.65 \\
\hline 1 & 0.66 \\
\hline
\end{tabular}

\subsection{Testing techniques}

2.4.1. Mechanical flexural test

The three (3) point flexural test was carried out on the specimens according to standard NFP 15-451. A force sensor and two LVDT type displacement sensors were mounted on the specimens in order to respectively determine the load and the deflection at the center of the latter. The flexural strength $\left(\tau_{\mathrm{f}}\right)$ and the strain $\left(\varepsilon_{\mathrm{f}}\right)$ are calculated from the formulas:

$$
\begin{aligned}
\tau_{f} & =\frac{3 F_{f} l}{2 b^{3}} \\
\varepsilon_{f} & =\frac{6 \varphi B}{l^{2}}
\end{aligned}
$$

where $F_{f}$ are the flexural load 1 are the distance between the two supports, $b$ are the side of the sample, $\varphi$ are the deflection of the specimen calculated in the middle and B are height of the specimen.

\subsubsection{Mechanical compression test}

The compression test is carried out on the two half-pieces obtained after flexural failure according to standard NFP 15-451. During these tests, force and displacement sensors are placed on the specimen in order to read the load and the shrinkage. The compressive stresses $\left(\sigma_{\mathrm{c}}\right)$ and the strain $\left(\varepsilon_{\mathrm{c}}\right)$ are calculated respectively from the following formulas:

$$
\begin{gathered}
\sigma_{c}=\frac{F_{c}}{b^{2}} \\
\varepsilon_{c}=\frac{\Delta b}{b_{0}}
\end{gathered}
$$

where $\Delta b$ is the shrinking of the sample, $b_{0}$ are the initial dimension of the sample, $F_{c}$ are the compression load. The flexural and compression mechanical strength were measured on 4 x 4 x $16 \mathrm{~cm}^{3}$ specimens.

\subsubsection{Processing of images obtained with a binocular magnifier}

A section is made in the $4 \times 4 \times 16 \mathrm{~cm}^{3}$ samples perpendicular to the side of $16 \mathrm{~cm}$ to $4 \mathrm{~cm}$ from the end. Then the sectioned surface of the small piece is observed with a binocular magnifier at the same magnification of (Gx10) while keeping the distance between the preparation and the objective constant. The images obtained are processed using the Image software. The distance between the edge of a fiber in these immediate neighbors is measured and then the average of the distances per image is calculated.

\section{RESULTS AND DISCUSSION}

\subsection{Size distribution, chemical and mineralogical composition of clay}

The particle size analyzes carried out on Dabou clay show that it consists of $52 \%$ clay, $47 \%$ silt and $1 \%$ fine sand (Figure 1) therefore belongs to the class of silty clays with a clay texture (Figure 2). 


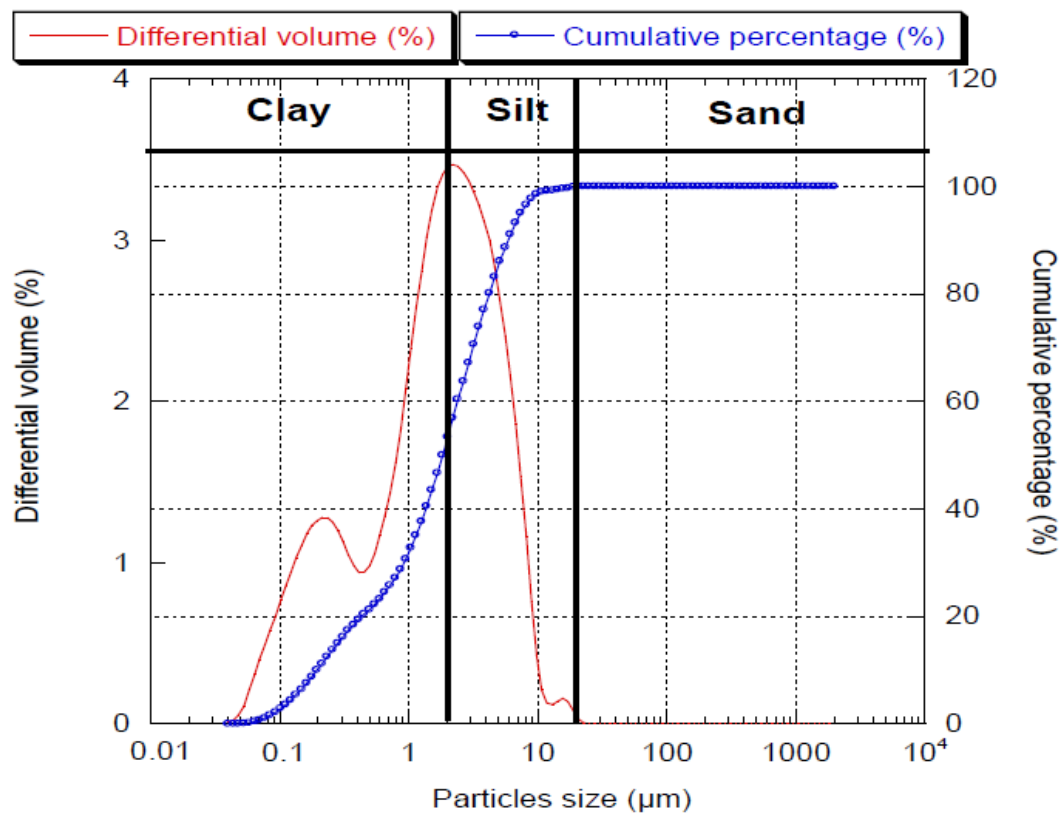

Fig. 1. Particle size distribution curve of clay.

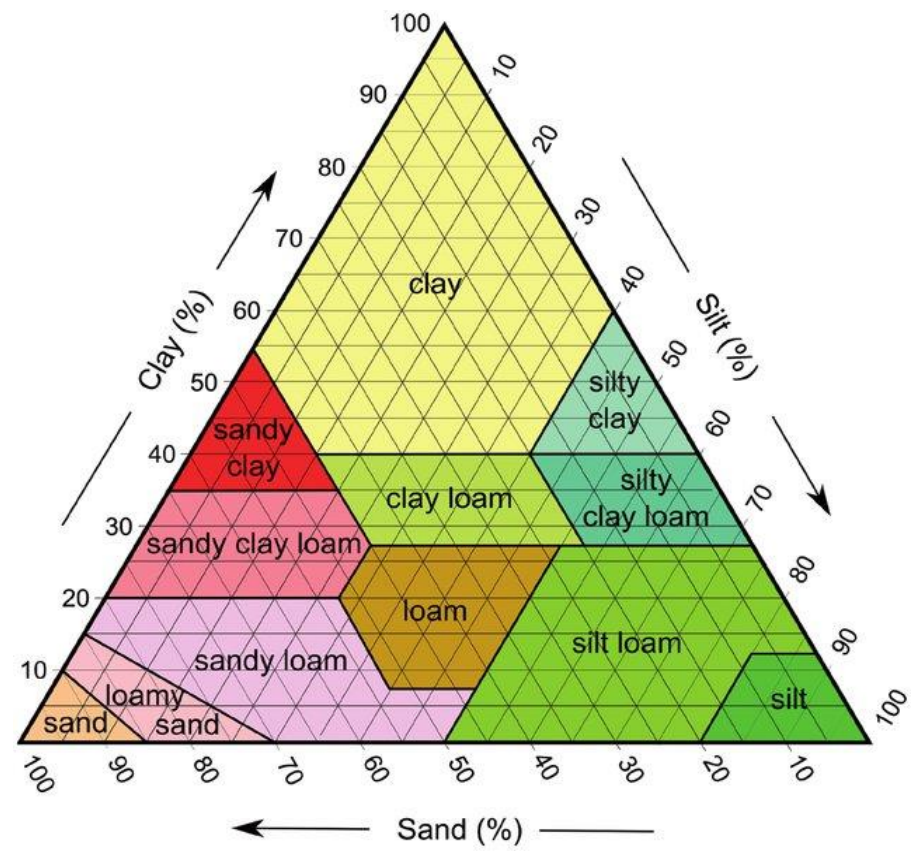

Fig. 2. Soil textural diagram [13].

Chemically in Table 2, the clay is mainly made up of two oxides: $\mathrm{SiO}_{2}(61.90 \%)$ and $\mathrm{Al}_{2} \mathrm{O}_{3}(21.22 \%)$. The minor oxides are $\mathrm{Fe}_{2} \mathrm{O}_{3}(4.36 \%), \mathrm{TiO}_{2}(1.42 \%)$ et $\mathrm{K}_{2} \mathrm{O}(1.53 \%)$. This mineralogical composition is illite $\left(\mathrm{KO}_{2} \mathrm{H}_{2} \mathrm{O}\right.$, $\left.2 \mathrm{Al}_{2}\left(\mathrm{Si}_{3} \mathrm{Al}\right) \mathrm{O}_{10}(\mathrm{OH})\right)$, kaolinite $\left(2 \mathrm{SiO}_{2}, \mathrm{Al}_{2} \mathrm{O}_{3}, 2 \mathrm{H}_{2} \mathrm{O}\right)$ and smectite $\left(2 \mathrm{Al}_{2} \mathrm{O}_{3}, 8 \mathrm{SiO}_{2} ; 2 \mathrm{H}_{2} \mathrm{O}, \mathrm{nH}_{2} \mathrm{O}\right)$ (Figure 3 ) accordance with the chemical composition.

Table 2. Chemical composition of clay.

\begin{tabular}{|c|l|l|l|l|l|l|l|l|l|l|l|}
\hline Oxides & $\mathrm{SiO}_{2}$ & $\mathrm{Al}_{2} \mathrm{O}_{3}$ & $\mathrm{Fe}_{2} \mathrm{O}_{3}$ & $\mathrm{TiO}_{2}$ & $\mathrm{~K}_{2} \mathrm{O}$ & $\mathrm{Na}_{2} \mathrm{O}$ & $\mathrm{CaO}$ & $\mathrm{SO}_{3}$ & $\mathrm{Cr}_{2} \mathrm{O}_{3}$ & $\mathrm{MgO}$ & $\mathrm{P}_{2} \mathrm{O}_{5}$ \\
\hline $\begin{array}{c}\text { Content } \\
(\%)\end{array}$ & 61.90 & 21.22 & 4.36 & 1.42 & 1.53 & 0.75 & 0.23 & 0.24 & 0.04 & 0.71 & 0.14 \\
\hline
\end{tabular}




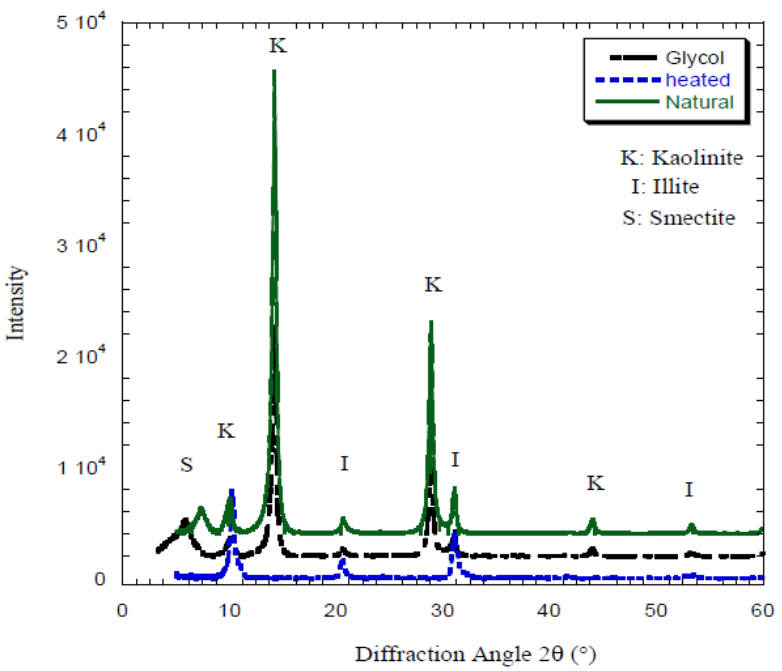

Fig. 3. X-ray diffraction curve of clay.

\subsection{Particle size and chemical composition of the cement}

Cement is essentially made up of three particle sizes, the most abundant of which is $67 \mu \mathrm{m}$ followed by $10 \mu \mathrm{m}$ and $0.3 \mu \mathrm{m}$ (Figure 4).

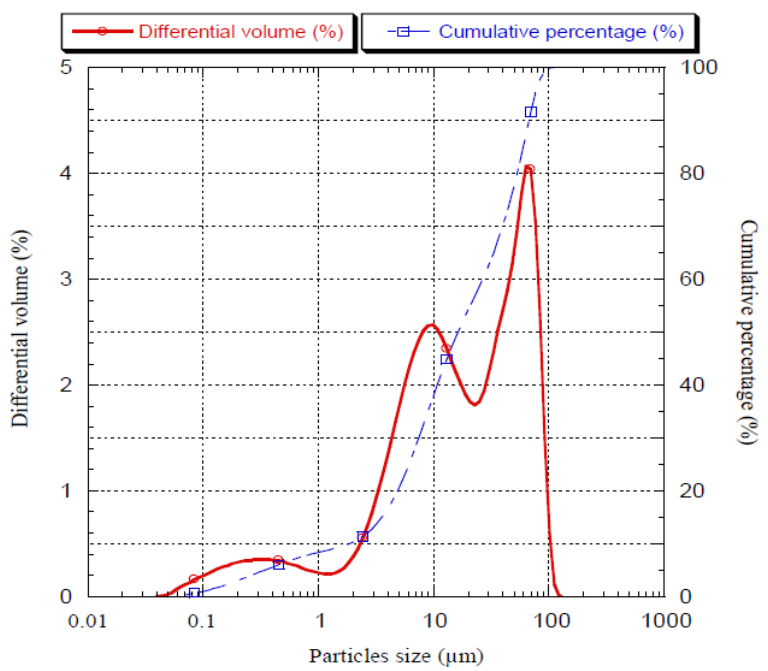

Fig. 4. Particle size distribution curve of cement.

This cement is coarser than clay because $50 \%$ of these particles are less than $16 \mu \mathrm{m}$ in size.

From the chemical point of view, in Table 3, cement consists essentially of $\mathrm{CaO}, \mathrm{SiO}_{2}, \mathrm{Al}_{2} \mathrm{O}_{3}$ and $\mathrm{Fe}_{2} \mathrm{O}_{3}$ which are the main constituents of clinker.

Table 3. Chemical composition of the cement.

\begin{tabular}{|l|l|l|l|l|l|l|l|l|l|l|l|}
\hline Oxides & $\mathrm{SiO}_{2}$ & $\mathrm{Al}_{2} \mathrm{O}_{3}$ & $\mathrm{Fe}_{2} \mathrm{O}_{3}$ & $\mathrm{TiO}_{2}$ & $\mathrm{~K}_{2} \mathrm{O}$ & $\mathrm{CaO}$ & $\mathrm{P}_{2} \mathrm{O}_{5}$ & $\mathrm{Na}_{2} \mathrm{O}$ & $\mathrm{SO}_{3}$ & $\mathrm{Cr}_{2} \mathrm{O}_{3}$ & $\mathrm{MgO}$ \\
\hline Content $(\%)$ & 21.29 & 2.51 & 3.14 & 0.15 & 0.55 & 60.32 & 0.19 & 0.43 & 2.99 & 0.02 & 1.39 \\
\hline
\end{tabular}

\subsection{Physical and mechanical properties of coconut fibers}

The physical and mechanical properties of coconut fibers are given in Table 4 . The absorption capacity of coconut fibers is lower than that of Hibiscus cannabinus [5] and sisal fibers [14]. However, its tensile strength is lower than that of hemp, sisal and Hibiscus cannabinus fibers. 
Table 4. Physical characteristics of coconut fibers.

\begin{tabular}{|c|c|}
\hline Parameters & Values \\
\hline Density $\left(\mathrm{g} / \mathrm{cm}^{3}\right)$ & 1.25 \\
\hline Water absorption $(\%)$ & 163 \\
\hline Tensile strength $(\mathrm{MPa})$ & 127.2 \\
\hline
\end{tabular}

\subsection{Mechanical behavior of blocks}

\subsubsection{Flexural}

Figure 5 shows the stress-strain curves obtained during the three-point flexural test. With the except for blocks not containing fibers where the curve is a straight line, they have the shape of a half-parabola whose end is located at the origin of the reference.

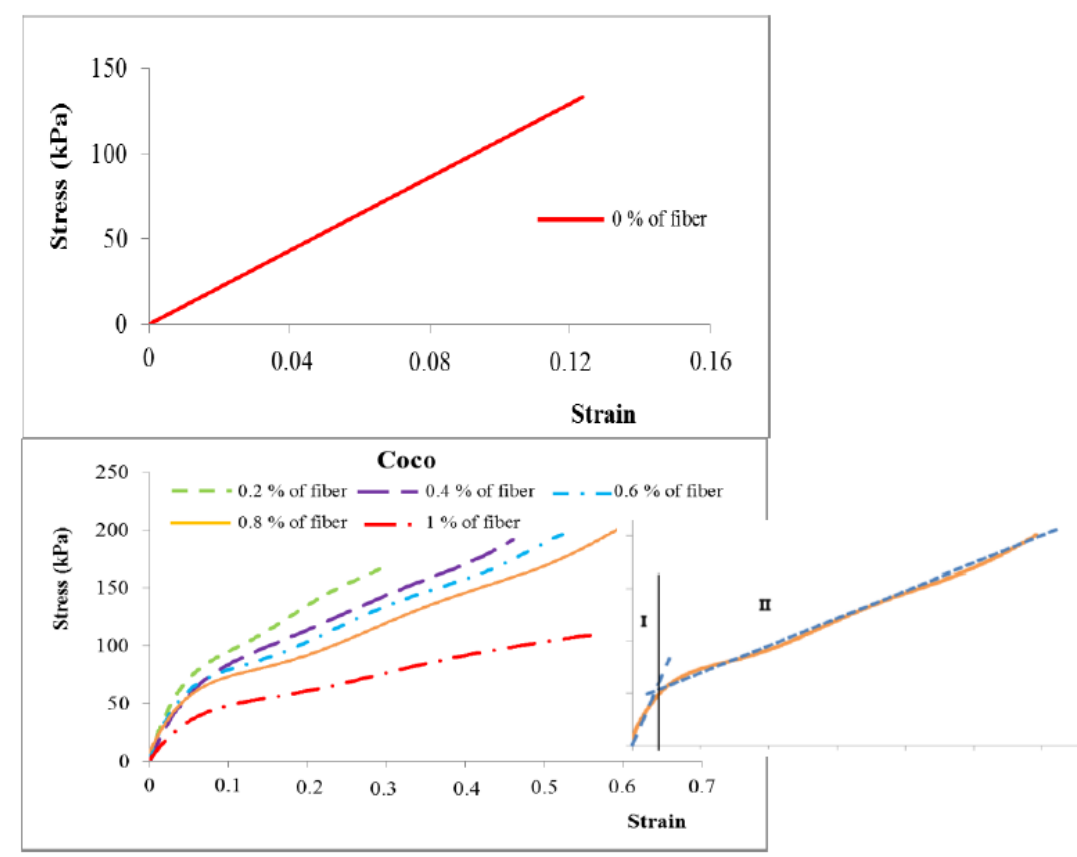

Fig. 5. Flexural stress-strain curve of blocs: I-domain I; II-domain II.

This curve can be divided into two parts. The first (domain I) corresponds to the half-line tangent to the stress strain curve at the origin. It has almost the same slope as the straight line obtained on the blocks without coconut fibers at the origin. The second (domain II) is given by the line tangent to the stress-strain curve from its end. This appearance of the flexural curves is explained by the resistance that the fibers oppose to the progression of the breaking front. During the stress, the crack is initiated in the clay-cement matrix at the level of the face placed on the supports then it propagates in the block when the stress increases. This propagation is done by opening (rupture mode I). When the block is made up solely of the clay-cement matrix, the material being homogeneous, the fracture front moves in the same way in the block, hence the proportionality between the stress and the deformation. When the block consists of the clay-cement matrix and the coconut fibers, the crack begins in the clay-cement matrix and then it progresses. During its displacement, the fracture front meets the coconut fibers which have a modulus of deformation different from that of the matrix.

The crack not being able to cross the fibers, will circumvent them from where the separation of the fibers from the matrix (Figure 6) which leads to the rupture of the samples.

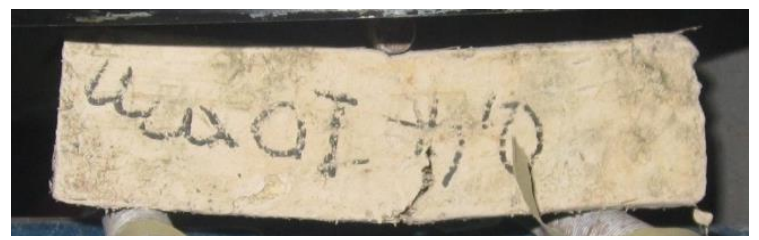

Fig. 6. Broken specimen showing a crack with the two pieces connected by the fibers. 


\subsubsection{Compression}

The mechanical behavior in compression of the blocks is presented on the stress strain curves in Figure 7.

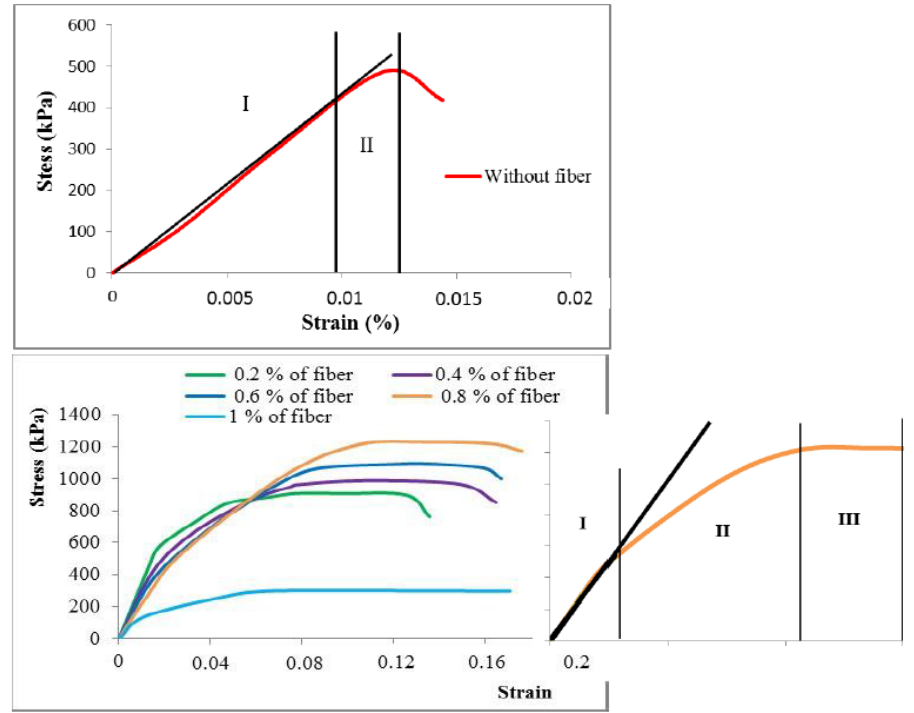

Fig. 7. Compressive stress-strain curve of blocs: I-domain I; II-domain II; III-domain III.

This figure shows that the behavior of the blocks varies with the fiber content. Fiber-free blocks are characterized by a practically elastic linear behavior until failure (Figure 7). It is identical to that determined by [15]. In reality, this is pseudo-elastic behavior because [16] show that during the charges and discharges carried out before rupture the material retains a deformation which remains acquired. The blocks containing fibers have an elastoplastic behavior with variable ductility in three phases regardless of the fiber content. The first phase (domain I) of linear elastic behavior, corresponds to the initiation of isolated microcracks in the blocks, more precisely in the cement clay matrix. It is followed by a second phase (domain II) of plastic behavior characterized by a non-linear curve. It corresponds to the progression of microcracks towards the zone of coalescence.

This progression is partly hampered by the presence of fibers. Finally comes the third phase (domain III) (Figure 7) which also corresponds to plastic behavior. However, it is characterized by the curve which is a straight line of practically zero slope.

During this phase, there is both a cold rolling (closure of certain microcracks) and a separation of the fibers of the matrix which leads to the rupture of the block. This same compression result is obtained by [17] on hemp concrete. He claims that hemp concrete has very ductile mechanical behavior, although hemp fibers have low ductility. Unlike [18] obtained in compression on hemp concrete an elastoplastic behavior.

Furthermore, this figure also shows that the magnitude of this third domain increases with the increase in the fiber content $30 \mathrm{~mm}$ long.

\subsection{Influence of fiber content on mechanical properties}

The influence of the fiber content on the mechanical strength of the blocks is given in Figure 8.

The addition of fiber in the blocks improves their resistance to flexural and compression. However, beyond $1 \%$ fiber, these weaken the blocks. In fact, in the blocks, the fibers are surrounded by the clay-cement matrix (Figure 9 ). When the fiber level increases, the fibers become entangled and the proportion of matrix around it gradually decreases. 


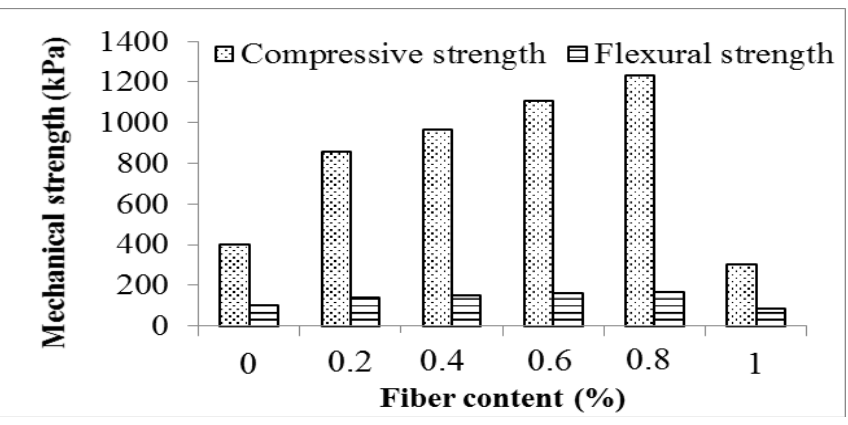

Fig. 8. Variation of strength in function of fibers content.
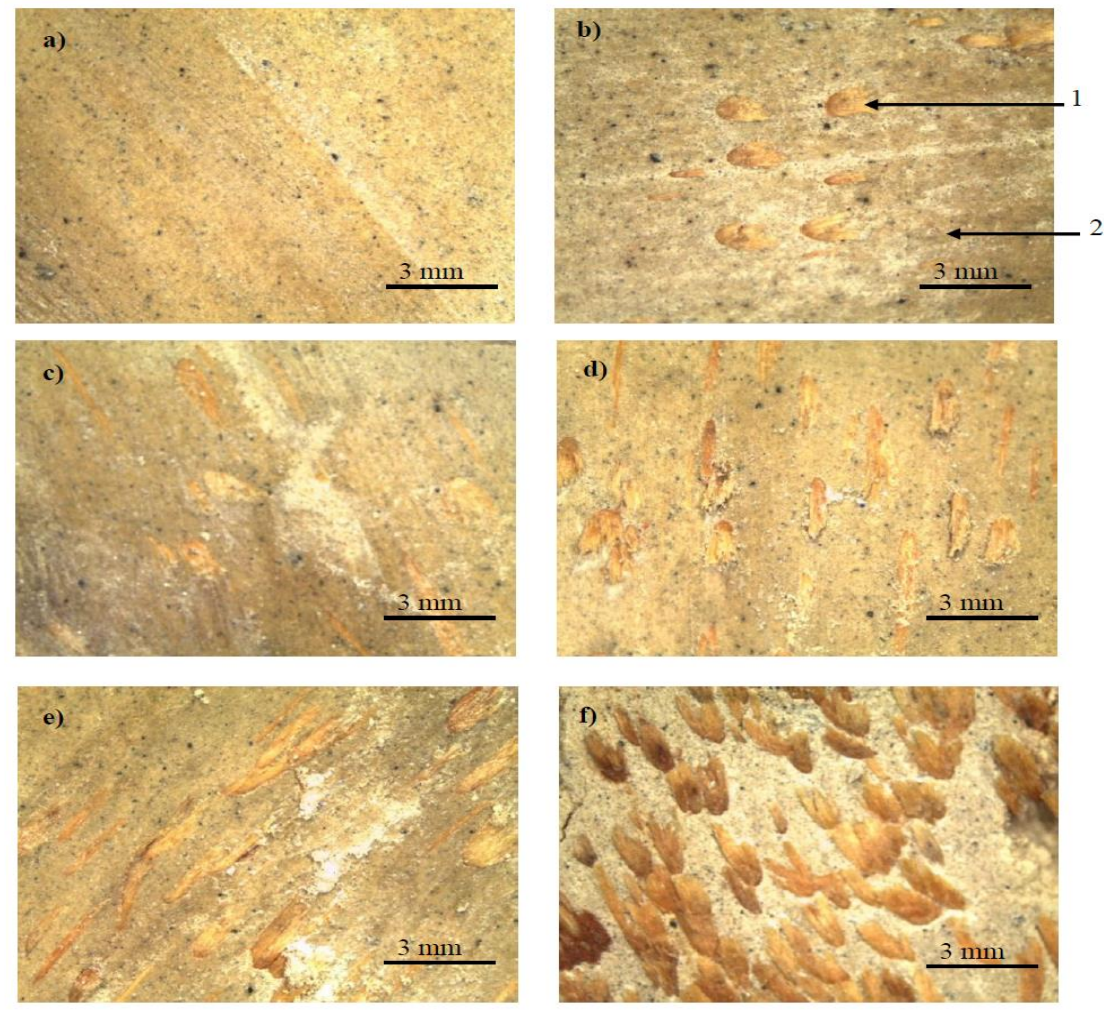

Fig. 9. Section view of the distribution of coconut fibers in the blocks: a) blocks with $0 \%$ fiber; b) block with $0.2 \%$ fibers; c) block with $0.4 \%$ fibers; d) block with $0,6 \%$ fiber; e) $0.8 \%$ fiber block; f) $1 \%$ fiber block: 1 - Coconut fibers; 2 - Clay-cement matrix.

Table 5 presents the distribution of the distances between the fibers for the different contents.

Table 5. Distribution of distances between fibers in each block.

\begin{tabular}{|c|c|c|c|}
\hline \multirow{2}{*}{$\begin{array}{c}\text { Fibers } \\
\text { content }(\%)\end{array}$} & \multicolumn{3}{|c|}{ Distance between fibers } \\
\hline 0 & Minimum $(\mathrm{mm})$ & Maximum $(\mathrm{mm})$ & Average $(\mathrm{mm})$ \\
\hline 0.2 & - & - & - \\
\hline 0.4 & 0.501 & 3.789 & 1.859 \\
\hline 0.6 & 0.183 & 3.303 & 1.569 \\
\hline 0.8 & 0.280 & 1.987 & 1.144 \\
\hline 1 & 0.201 & 2.361 & 0.829 \\
\hline
\end{tabular}

Overall, it indicates that the average distance between a fiber and these immediate neighbors decreases with increasing fiber content. Thus, the increase in strength with the fiber content would be due to the approximation between the fibers (Figure 10). 
There is an optimal distance for which the strength is maximum, and which allows a better adhesion fiber matrix fiber. Below this distance, the fibers being too close, and the structure of the block is weakened. Therefore the flexural strength drops to more than $0.8 \%$ fiber. This optimum distance between fibers in the cement clay matrix is around $0.8 \mathrm{~mm}$ or so.
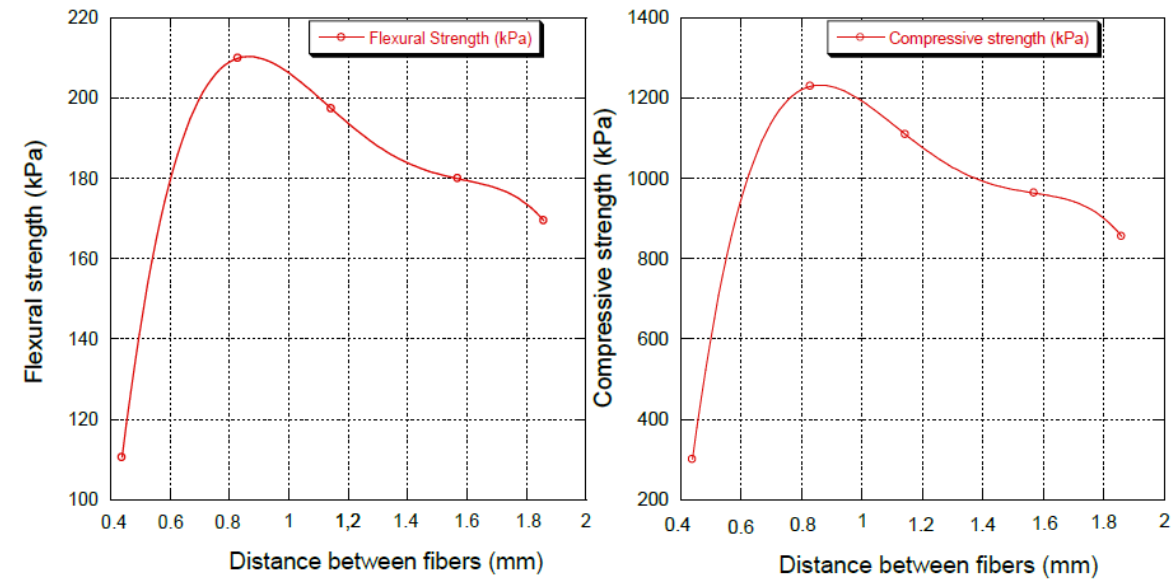

Fig. 10. Variation in mechanical resistance as a function of the distance between the fibers.

\subsection{Relationship between flexural and compressive strength}

Figure 11 illustrates the evolution of compression stresses as a function of that of flexure. It shows that the two properties are strongly correlated. In general, the compressive strength increases according to a power function compared to the flexural strength. The experimentally determined expression which relates the compressive strength, and the three-point flexural strength of the composites is of the form $R_{c}=0.023 R_{f}^{2.1275}$. A similar expression $\left(R_{t f}=m R_{c}{ }^{n}\right)$ which links the tensile strength by splitting $\left(R_{t f}\right)$ and the compressive strength $\left(R_{c}\right)$ was obtained by [19].

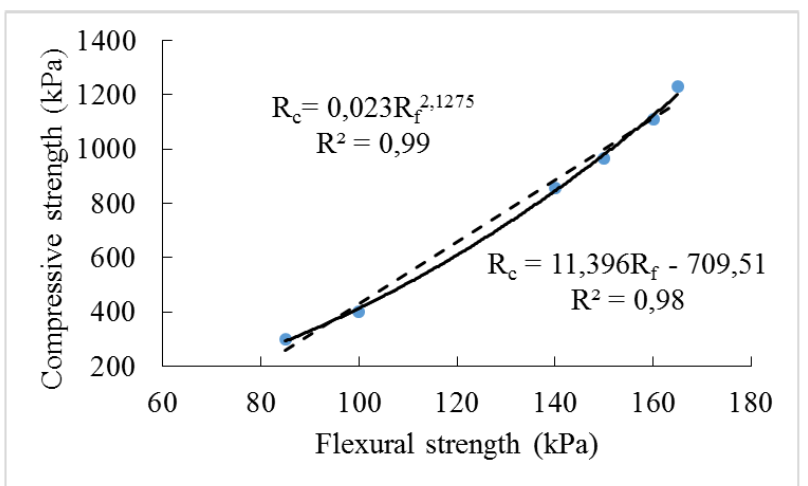

Fig. 11. Relation between flexural and compressive strength.

Figure 11 shows again the compressive strength increases in linear function with the flexural strength. The relation which binds the two resistances determined experimentally is of the form $R_{c}=11.396 R_{f}-709.51$. Expression of this form has been obtained on BTC [20]. In this work both relationships are verified because of the low values of compressive and flexural strength.

\section{CONCLUSIONS}

The mechanical behavior of the blocks obtained by casting clay-cement reinforced with coconut fiber was analyzed. The following conclusions emerge from this study:

- The compressive strength of clay cement blocks with $0.8 \%$ fiber is sufficient for them to be used as filler materials or partition walls in building construction;

- Clay cement blocks containing coconut fibers have higher flexural strength than those without fiber. Adding less than $1 \%$ fiber to the blocks increases their ability to resist crack propagation. 


\begin{abstract}
- The behavior under axial stress of cast blocks reinforced with coconut fibers is elastoplastic with a phase of ductile behavior whose magnitude increases with the fiber content.

- Clay cement blocks containing $0.8 \%$ fiber have the best structural organization with an average fiber gap of 0.8 $\mathrm{mm}$.

- The relation between the flexural strength $\left(R_{f}\right)$ and the compressive strength $\left(R_{c}\right)$ is of the form $R_{c}=m R_{f}{ }^{n}$ and/or $\mathrm{R}_{\mathrm{c}}=\mathrm{aR}_{\mathrm{f}}-\mathrm{b}$.
\end{abstract}

\title{
REFERENCES
}

[1] Christophe, J.D., La bouse: historique, importance et écosystème, Thèse de doctorat vétérinaire, Ecole Nationale Vétérinaire de Toulouse, 2004, p. 82.

[2] Quagliarini, E., Lenci, S., The influence of natural stabilizers and natural fibres on the mechanical properties of ancient Roman adobe bricks, Journal of Cultural Heritage, vol. 11, no. 3, 2010, p. 309-314.

[3] Galàn-Marin, C., Rivera-Gomez, C., Petric, J., Clay-based composite stabilized with natural polymer and fibre, Construction and Building Material, vol. 24, 2010, p. 1462-1468.

[4] Juàrez, C., Guevara, B., Duràn-Herrera, A., Mechanical properties of natural fibers reinforced sustainable masonry, Construction and Building Material, vol. 24, 2010, p. 1536-1541.

[5] Millogo, Y., Morel, J.C., Aubert, J.E., Ghavami, K., Experimental analysis of pressed adobe reinforced with Hibiscus cannabinus fibers, Construction and Building Material, vol. 52, 2014, p. 71-78.

[6] Ghavami, K., Filho, D.T., Barbosac, N.P., Behaviour of composite soil reinforced with natural fibres, Cement and Concrete Composites, vol. 21, 1999, p. 39-48.

[7] Saadi, I., Belouettar, R., Comportement mécanique des briques de terre crue renforcées par des fibres de palmier dattier et des fibres de paille, Séminaire International, Innovation and Valorisation en Genie Civil and Materiaux de Construction, 2011, p. 118.

[8] Khedari, J., Charoenvai, S., Hirunlabh, J., New insulating particleboards from durian peel and coconut coir, Build Environment, vol. 38, no.3, 2003, p. 245-254.

[9] Namango, S.S., Development of cost-effective earthen building material for housing wall construction: investigations into the properties of compressed earth blocks stabilized with sisal vegetable fibres. cassava powder and cement compositions, Thesis, Brandenburg Technical University, Cottbus, Germany, 2006.

[10] Salehan, I., Yaacob, Z., Properties of laterite brick reinforced with oil palm empty fruit bunch fibers, Pertanika Journal of Science and Technology, vol. 19, no. 1, 2011, p. 33-43.

[11] Taallah, B., Guettala, A., Kriker, A., Effet de la teneur en fibres de palmier dattier et de la contrainte de compactage sur les propriétés des blocs de terre comprimée, Courrier du Savoir, no. 18, 2014, p. 45-51.

[12] Villamizar, M.C.N., Araque, V.S., Reyes, C.A.R., Silva, R.S., Effect of the addition of coalash and cassava peels on the engineering properties of compressed earth blocks, Construction and Building Materials, vol. 36, no. 11, 2012, p. 276-286.

[13] Duchaufour, P., Agrégé de pédologie: sol, végétation, environnement, Ed. Masson, 1997, p. 291.

[14] Laborel-Préneron, J.E., Aubert, C., Magniont, C., Tribout, A.B., Plant aggregates and fibers in earth construction materials: A review, Construction and Building Materials, vol. 111, 2016, p. 719-734.

[15] Mestat, Ph., Reiffsteck, Ph, Modules de deformation en mécanique des sols: définition, determination à partir des essais triaxiaux et incertitude. Paramètres de calculs geotechnique, Ed. Magan, 2002, p. 8.

[16] Kouakou, C.H., Morel, J.C., Strength and elasto-plastic properties of non-industrial building materials manufactured with clay as a natural binder, Applied Clay Science, vol. 44, no. 1-2, 2009, p. 27-34.

[17] Nguyen, T.T., Contribution à l'étude de la formulation et du procédé de fabrication d'éléments de construction en béton de chanvre, Thesis, Université de Bretagne Sud, 2010.

[18] Cerezo, V., Propriétés mécaniques, thermiques et acoustiques d'un matériau à base de particules végétales: approche expérimentale et modélisation théorique, Thesis, Ecole Nationale des Travaux Publics de l'Etat, Lyon, 2005, p. 248.

[19] Zain, M.F.M., Mahmud, H.B., Ilham, A., Faizal, M., Prediction of splitting tensile of high-performance concrete, Cement and Concrete Research, vol. 32, no. 8, 2002, p. 1251-1258.

[20] Ablo, P., Caractérisation et compression simple des blocs de terre comprimée (BTC): application aux maçonneries BTC-mortier de terre, Thesis, Ecole Nationale des travaux Publics de l'Etat (ENTPE), 2002, p. 171. 